\title{
Field observations and remote sensing techniques for evaluation of vegetal recovery after different wildfire severity in a Mediterranean ecosystem
}

\author{
Observaciones en terreno y técnicas de teledetección para evaluar la recuperación vegetal \\ después de un incendio forestal de diferente severidad en el ecosistema mediterráneo
}

\author{
Marcos Francos ${ }^{a *}$, Marc Lemus-Canovas ${ }^{b}$ \\ *Corresponding author: ${ }^{a}$ Universidad de Tarapacá, Facultad de Educación y Humanidades, \\ Departamento de Ciencias Históricas y Geográficas, 18 de Septiembre 2222, Arica, Chile, \\ tel.: +56942774326, marcosfrancos91@gmail.com \\ ${ }^{\mathrm{b}}$ University of Barcelona, Faculty of History and Geography, Department of Geography, Barcelona, Spain.
}

\begin{abstract}
SUMMARY
Many studies of Mediterranean ecosystems have analyzed vegetation recovery after a wildfire based on fieldwork or remote sensing; however, only a few have adopted a multi-approach assessment. The aim of this study is to determine the viability of a multi-approach using vegetation and remote sensing to observe vegetation recovery time in areas with different wildfire severity. The study area is located in a Mediterranean forest of North-east Spain. After a wildfire, low-, medium- and high- severities with an unburned control were delimited and inventoried at short-, medium- and long-terms using a 20-m transect; measurements were taken in a 1-m width. In each area, vegetal richness (S), diversity (H') and density (D) were measured using fieldwork. The differenced Normalized Burnt Ratio (dNBR) and Mean Decrease Accuracy (\%incMSE) were calculated and quantified. Both methods result to be accurate in studying plant density. The dNBR index decreases over time as an effect of the disappearance of fire disturbance. Topographic and vegetation variables help explain the fire severity at very-short and short-terms, while at medium- and long-terms any explanatory power is virtually lost. Partial dependence allowed us to identify those areas that suffered higher fire severity and vegetal evolution over time.
\end{abstract}

Key words: fire ecology, Mediterranean forest, remote sensing, partial dependence, wildfire severity.

\section{RESUMEN}

Muchos estudios de los ecosistemas mediterráneos han analizado la recuperación de la vegetación después de un incendio forestal, basándose en el trabajo de campo o en la teledetección; sin embargo, solo unos pocos han adoptado una evaluación con ambos enfoques. El objetivo de este estudio es determinar la viabilidad de un enfoque múltiple que utilice el trabajo en terreno y la teledetección para observar el tiempo de recuperación de la vegetación en zonas con diferente severidad tras un incendio forestal. La zona de estudio está situada en un bosque Mediterráneo del noreste de España. Después de un incendio forestal, se delimitaron e inventariaron las severidades bajas, medias y altas con un control sin quemar a corto, medio y largo plazo, utilizando un transecto de $20 \mathrm{~m}$ tomando las medidas en un ancho de $1 \mathrm{~m}$. En cada zona se midió la riqueza (S), la diversidad (H') y la densidad (D) vegetal mediante trabajo de campo. Se calculó y cuantificó la diferencia entre el índice normalizado de quemado (dNBR) y la precisión de la disminución media (\%incMSE). Ambos métodos resultan ser muy exhaustivos en el estudio de la densidad vegetal. El índice dNBR disminuye con el tiempo como efecto de la desaparición de la perturbación por incendio. Las variables topográficas y de vegetación ayudan a explicar la severidad del fuego a muy corto y corto plazo, mientras que a medio y largo plazo prácticamente se pierde toda capacidad explicativa. La dependencia parcial permitió identificar aquellas áreas que sufrieron una mayor severidad del fuego y la evolución vegetal a lo largo del tiempo.

Palabras clave: ecología del fuego, bosque mediterráneo, teledetección, dependencia parcial, severidad de un incendio forestal.

\section{INTRODUCTION}

Wildfires are a natural element in Mediterranean ecosystems (Keeley et al. 2011). Many factors influence the evolution of soil properties as topography (Dillon et al. 2011), fire intensity (Keeley 2009), post-fire weather conditions and forest management practices (Francos et al.
2020). The combination of all of these factors results in fire severity. Fire intensity is a physical measurement of the heat or the energy released on the front of disturbance, while severity is the ecological consequences of the fire effect. Burn severity is almost equivalent to fire severity. Although fire intensity is a key driver of severity, it is not the only because severity results from fire-duration, -fre- 
quency, -size and -season (Keeley 2009). One of the main and visual impacts of wildfires is the consumption of vegetation cover: the higher the fire intensity, the higher this consumption (Pausas and Keeley 2014). In Mediterranean environments, fire severity is a key factor in determining post-fire plant recovery given the marked differences identified in the speed of recovery of resprouters, on the one hand, and seeders, on the other (Keeley 2009). In areas where fire severity has been high, the seed bank is likely to be affected, all the vegetation is consumed and mostly resprouters will colonize the area (Pausas and Keeley 2014). However, in those areas where fire severity remained moderate, seeders compete with resprouters in the process of colonization. Meanwhile in areas affected by fires with a low degree of severity, we tend to see an increase in vegetation richness compared, above all, with areas unaffected by fire (Madrigal et al. 2011). More specifically, wildfires, depending again on their severity, can reduce woody plant richness; while in herbaceous plants fire impacts richness (S), diversity (H') and density (D) for periods that may extend many years (Bond and Keeley 2005). In areas unaffected by fire for long periods, tree density increases while herbaceous diversity falls, resulting in a forest structure different from that previously recorded and a significant accumulation of fuel that may result in extremely severe forest fires (Bond and Keeley 2005).

Fire severity has traditionally been evaluated by fieldwork or from an airborne platform, followed by the categorized manual mapping of the damage generated by fire. However, since the introduction of the Landsat satellite program (since 1972), it has been possible to estimate fire severity periodically and at a much lower cost. Indeed, the quantification of fire severity using remote sensing images has been addressed in some studies and using a wide variety of statistical methods (Zheng et al. 2018). One of the most commonly used indices to quantify the severity of a fire is the Normalized Burn Ratio (NBR) (Key and Benson 2006), specifically created to evaluate wildfire intensity. However, the key to a successful quantification of burn severity is to be able to calculate the difference between pre- and post-fire NBRs, that is, the differenced Normalized Burn Ratio (dNBR), the application of which has been tested in several studies with satisfactory results (BentoGonçalves et al. 2019).

A few studies have sought to evaluate burn severity by modelling forest topographic factors, on the understanding that topography directly affects both vegetation dynamics and fire behavior (Dillon et al. 2011). Long-term studies of forest vegetation indices are critical for evaluating an ecosystem's capacity to recover its pre-fire conditions (Martínez et al. 2019). Here, the combination of field and satellite observations provides additional information for a better understanding of vegetation recovery capacity over time after fire disturbance and helps to establish the limitations of each of the methods used (Parks et al. 2014, Martínez et al. 2019). The aim of this study is to determine the accuracy of such a multi-approach to the assessment of vegetation recovery in short, medium and long terms in areas affected by low-, medium- and high-severity wildfires. Additionally, the study seeks 1) to compare the fieldwork observation and remote sensing methods and to identify their relative strengths and weaknesses for the analysis of post-fire plant regeneration from short- to medium- and long-terms; 2) to analyze the degree of interdependence between burn-severity, computed as the differenced normalized burn ratio (dNBR), and the landscape and pre-fire vegetation status in a small burned area (55 ha); and finally 3 ) to identify potential factors that might predict higher burn severity in complex topographic terrains. Our hypothesis is that forests present a high resilience to wildfire disturbance and that the comparison of both methods allows us to be more accurate in our studies. The study provides a novel comparison of two methods for the study of vegetal recovery after a forest fire in different fire severity areas over time from short- to medium- and long-terms.

\section{METHODS}

Study Area and vegetation inventory. The study area is located in Cadiretes Massif, NE Spain at an altitude between 190 and $325 \mathrm{~m}$ a.s.l. (figure 1). The study area and its wildfire dynamics have been described in detail in Úbeda et al. (2006) and Francos et al. (2016). Soils in the control and low-severity fire areas are predominantly composed of granites and are classified as Typic Haploxerept, while those in medium- and high-severity fire areas are predominantly Lithic Haploxerept (Úbeda et al. 2006). Land cover is mainly composed by mixed forest (figure 2). Vegetation is mainly composed of Quercus suber L., Arbutus unedo L., Erica arborea L., and Pinus pinaster spp. Mean annual rainfall ranges between 700 and $800 \mathrm{~mm}$.

The wildfire event studied here broke out on 5 July 1994 and consumed a total of 55 ha. The wildfire did not burn with the same intensity throughout the study area, with fire severities being determined just after the event during fieldwork, based on soil and vegetation characteristics, as described in Úbeda et al. (2006). Just after the wildfire, three burned areas were identified: a) Low-severity area (where trees retained some leaves and a large number of branches, including smaller ones); b) Medium-severity area (where trees retained no leaves though a considerable number of branches); c) High-severity area (where trees lost all leaves and branches), and compared with d) an unburned area (Control) (figure 1).

Vegetation inventories were conducted in the short-, medium- and long-terms (Úbeda et al. 2006, Francos et al. 2016). These inventories were carried out in each of the four areas at three different sampling times and consisted of transects that were $20 \mathrm{~m}$ long and $1 \mathrm{~m}$ wide, so that the total area for each transect was $20 \mathrm{~m}^{2}$. The same methods have been used in other post-fire vegetation recovery stu- 
dies to analyze the changes over time in small-scale fireaffected areas and with single inventories (Zheng et al. 2018). The name and quantity of each species were surveyed and the vegetation inventory richness (S), diversity $\left(\mathrm{H}^{\prime}\right)$ and density (D) were measured following Francos $e t$ al. (2020). S represents the number of plant species in each plot; evenness (It) is a measure of the relative abundance of the different species and D is the It/plot measure (in $\mathrm{m}^{2}$ ). Diversity was analyzed using the Shannon Diversity Index, where $H^{\prime}=-\sum p_{i}\left(\operatorname{In} p_{i}\right)$, and $p_{i}$ is the proportion

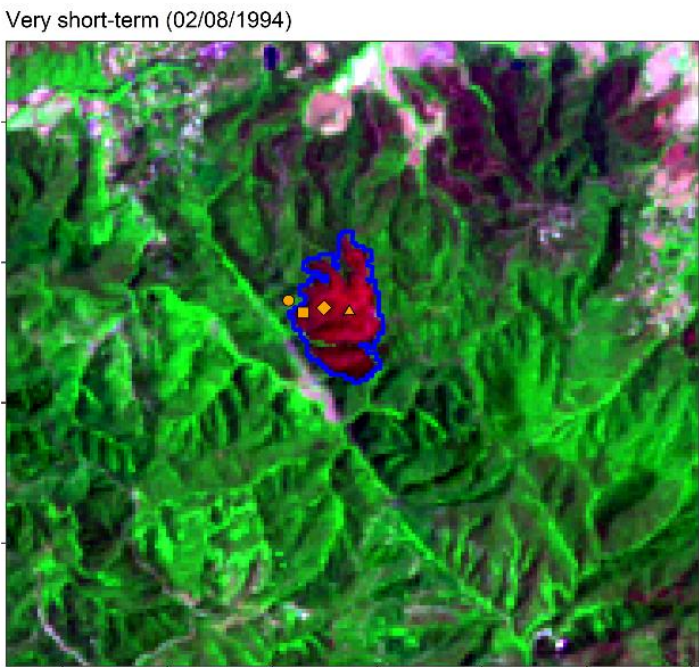

- Control area

$\diamond$ Medium-severity area

$\square$ Low-severity area
$\Delta$ High-severity area area

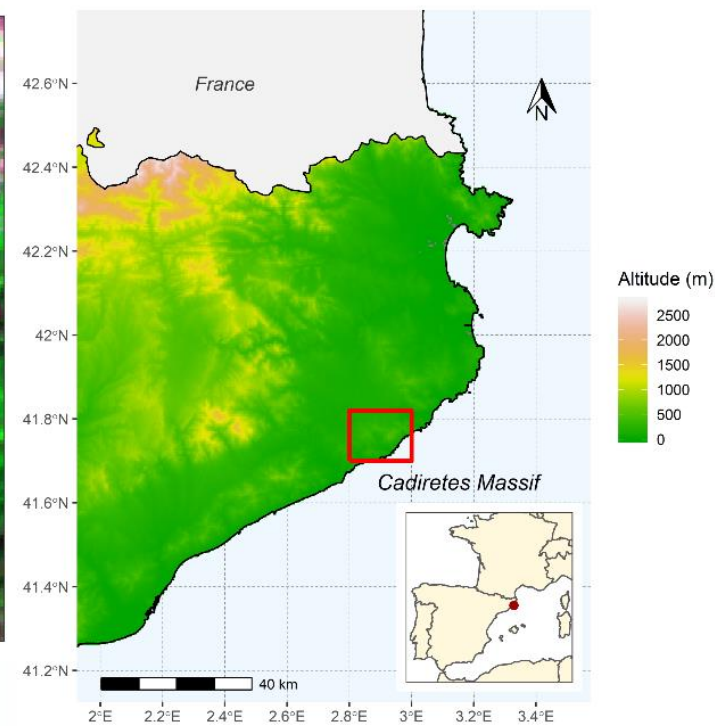

Figure 1. Location of the study area.

Localización del área de estudio.

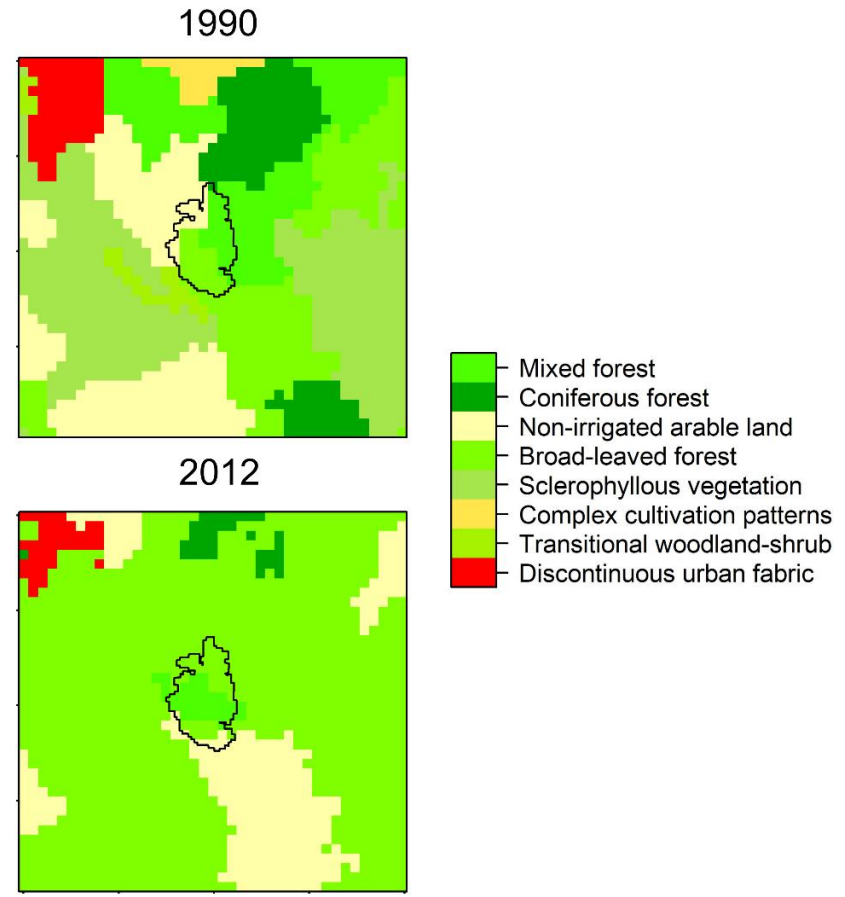

Figure 2. Land cover classes before (1990) and after (2012) the wildfire, provided by the pan-European CORINE land cover classification. Clases de cobertura del suelo antes (1990) y después (2012) del incendio forestal, proporcionadas por la clasificación pan-europea CORINE. 
of individuals of each species. Evenness results were not used as the dynamics and differences among the studied areas were the same as those obtained for D. In the inventories, we counted the number of individuals of each species (in line with previous studies) to determine changes in the percentage plant cover and species composition, taking into account their regenerative capacity and life form. To estimate the post-fire plant dynamics requires a knowledge of the germinating strategies of the species that make up the plant community (table 1).

Remote sensing image processing. The remote sensing images used in this study (table 2) were sourced from the USGS Earth Explorer web service and georeferenced to the terrain correction level (Level 1T). The radiometric correction of these images was performed using the dark object subtraction (DOS) model (Chavez 1988).

NBR maximizes changes in reflectance in vegetation and soil due to drastic changes, such as those produced by wildfire and despite the creation of new indexes (i.e. RdNVR); NBR resulted a good tool to study the vegetal reflec- tance (Parks et al. 2014). This index combines the near-infrared (NIR) and short-wave infrared (SWIR) bands (Key and Benson 2006). In the case of Landsat 5 and Landsat 7 , bands 4 and 7 are used as follows:

$$
\mathrm{NBR}=(\text { Band } 4-\text { Band } 7) /(\text { Band } 4+\text { Band } 7)
$$

To better isolate and separate burned and unburned areas and provide a quantitative measure of change, $\triangle \mathrm{NBR}$ (Key and Benson 2006) is calculated:

$$
\Delta \mathrm{NBR}=\mathrm{NBR}_{\text {pre-fire }}-\mathrm{NBR}_{\text {post-fire }}
$$

Unchanged areas will typically record values around zero, while burned areas present values above 0.1. $\triangle \mathrm{NBR}$ generates a continuous index ranging from unburned to severely burned areas. As can be seen in table 2, we applied the two types of assessment proposed by Key and Benson (2006). The initial assessment refers here to the severity of the burned area, according to images from Landsat scenes taken just after the fire, i.e. a very short term. The extended

Table 1. Species surveyed in the four study areas, their main regenerative capacity and life form.

\begin{tabular}{|c|c|c|}
\hline Species & Main regenerative capacity & Life form \\
\hline Arbutus unedo L. & Resprouter & Shrubs \\
\hline Brachypodium phoenicoides L. & Resprouter & Herbs \\
\hline Brachypodium retusum Pers. & Resprouter & Herbs \\
\hline Calicotome spinosa $\mathrm{L}$. & Seeder/Resprouter & Shrubs \\
\hline Calluna vulgaris L. & Seeder & Scrubs \\
\hline Centaurea L. & Seeder & Herbs \\
\hline Cistus monspeliensis L. & Seeder & Shrubs \\
\hline Cistus salviifolius L. & Seeder/Resprouter & Shrubs \\
\hline Erica arborea $\mathrm{L}$. & Resprouter & Shrubs \\
\hline Hedera helix L. & Resprouter & Shrubs \\
\hline Lonicera implexa Aiton. & Resprouter & Shrub/Liana \\
\hline Pinus pinaster Ait. & Seeder & Tree \\
\hline Pistacea lentiscus L. & Resprouter & Shrubs \\
\hline Quercus pubescens Willd. & Resprouter & Tree \\
\hline Quercus suber L. & Resprouter & Tree \\
\hline Rubus ulmifolius Schott. & Resprouter & Shrubs \\
\hline Rubia peregrina $\mathrm{L}$. & Resprouter & Liana/Herb \\
\hline Ruscus aculeatus L. & Resprouter & Shrubs \\
\hline Smilax aspera L. & Resprouter & Shrub/Liana \\
\hline Thapsia garganica L. & Seeder & Herbs \\
\hline Viburnum tinus L. & Resprouter & Shrubs \\
\hline
\end{tabular}

Especies estudiadas en las cuatro áreas de estudio, su principal capacidad regenerativa y su forma de vida. 
assessment, on the other hand, draws on Landsat scenes taken within different time ranges (short, medium and long terms). In both assessments, the scene used as a pre-fire evaluation is very close to that of the date of the fire.

Geospatial modelling of burn severity. To analyze the influence of topographic factors and pre-fire vegetation status on post-fire burn severity, we used random forest models (Breiman 2001). This approach allowed us to estimate the importance of each predictor variable and to adjust nonlinear relationships between the response and that variable. The degree of importance of predictor variables is assessed by \%incMSE, which shows how much our model accuracy decreases if we leave out that variable. In this study, we examined three predictor variables: altitude, slope-degree and pre-fire normalized difference vegetation index (NDVI). All variables were resampled at the same spatial resolution as the Landsat scenes $(30 \mathrm{~m})$. The use of climate variables, such as precipitation and temperature, was ruled out given the size of the area, with no marked climate contrasts being appreciable. For each of the models applied, we extracted the predictor variable importance, the explained variance and the $\mathrm{R}^{2}$. To illustrate the influence of each predictor variable on the response variable (which in our case is $\triangle \mathrm{NBR}$ ), we used the partial dependence plot (PD plot). Plots of this kind show the marginal

Table 2. Remote sensing images used in this study.

Imágenes de teledetección utilizadas en este estudio.

\begin{tabular}{ccc}
\hline & Image date & Sensor \\
\hline Pre-fire & $01 / 07 / 1994$ & Landsat 5 \\
Fire & $05 / 07 / 1994$ & - \\
Very short term & $2 / 08 / 1994$ & Landsat 5 \\
Short term & $21 / 12 / 1994$ & Landsat 5 \\
Medium term & $28 / 07 / 2004$ & Landsat 5 \\
Long term & $10 / 07 / 2012$ & Landsat 7 \\
\hline
\end{tabular}

effect of one or two predictor variables on the expected result of a random forest model or any other machine learning model. A PD plot can show whether the relationship between the predictor variable and the response variable is linear or nonlinear, an outcome that is dependent on the previously adjusted model. To generate the PD plots, we used the R package "pdp" (Greenwell 2017).

\section{RESULTS}

Vegetation recovery. The control area was mainly occupied by shrubs (71.4\%), herbs and trees (both $14.3 \%$ ). In the case of the area affected by low-severity fire, in the short term. The area was occupied by shrubs and trees in a proportion similar to that shown by the control. In the medium term, shrubs became dominant, while in the long term, herbs were dominant occupying almost $50 \%$ of the area, followed by shrubs, trees and finally scrubs. In the case of the area affected by medium-severity fire, in the short term, the area was occupied by shrubs $(68.4 \%)$ and trees $(31.6 \%)$, in the medium term by a similar proportion of shrubs and trees, and in the long term by herbs $(43.2$ $\%)$, shrubs $(37.5 \%)$, trees $(14.8 \%)$ and scrubs $(4.6 \%)$. Finally, in the case of the area affected by high-severity fire, in the short term, the area was occupied by a predominance of shrubs $(84.6 \%)$ and trees $(15.4 \%)$, in the medium term by shrubs $(90.7 \%)$ and trees $(9.3 \%)$, and in the long term by shrubs $(59.0 \%)$, herbs $(34.2 \%)$ and trees $(6.8 \%)$ (table 3$)$.

Comparison of methods and statistical analysis. This section compares the vegetation indices obtained from fieldwork with the remote sensing data. In the case of the dNBR at the four sampling times, the index was categorized (figure 2) in line with the categories established in Key and Benson (2006). Only six months separated the very short and short terms, which meant that virtually no highseverity burning could be detected in this period of rapid vegetation regeneration and different season (Parks et al. 2014). From the medium-term onwards, the vast majority of the burned area appears as unburned.

Table 3. Percentage of individuals grouped by life form for each area and each inventory sampling.

Porcentaje de individuos agrupados por forma de vida para cada área y cada inventario.

\begin{tabular}{cccccccccccccc}
\hline Area & \multicolumn{3}{c}{ Control } & \multicolumn{4}{c}{ Low-Severity } & \multicolumn{3}{c}{ Medium-Severity } & \multicolumn{3}{c}{ High-Severity } \\
\hline Life form/ Inventory & Short & Med & Long & Short & Med & Long & Short & Med & Long & Short & Med & Long \\
\hline Herbs & 14.3 & 14.3 & 14.3 & - & - & 48.8 & - & - & 43.2 & - & - & 34.2 \\
Scrubs & - & - & - & - & - & 7.0 & - & - & 4.5 & - & - & - \\
Shrubs & 71.4 & 71.4 & 71.4 & 46.2 & 78.1 & 29.1 & 68.4 & 65.3 & 37.5 & 84.6 & 90.7 & 59.0 \\
Trees & 14.3 & 14.3 & 14.3 & 53.8 & 21.9 & 15.1 & 31.6 & 34.7 & 14.8 & 15.4 & 9.3 & 6.8 \\
Total vegetation cover & 46.3 & 46.3 & 46.3 & 56.5 & 85.5 & 100 & 26.3 & 87.1 & 100 & 51.3 & 91.5 & 100 \\
\hline
\end{tabular}


The dNBR index was high, indicative of superior disturbance, depending on the regenerative capacity of each species. As figure 3 highlights, severity and degree of disturbance decrease over time throughout the study area. $\mathrm{S}$ was higher in the control area than in the other areas. The values obtained were 16 in the control area in short, medium and long terms; 6 in the low-severity area in the short term, 7 in the medium and 11 in the long term. In the medium-severity area, the values recorded were 6,6 and 12 in short, medium and long terms, respectively. In the high severity area, values were 6,7 and 9 , respectively, in short, medium and long terms. H' was 0.3810 in the control area in short, medium and long terms; 0.1132 in the low-severity area in the short term, 0.0946 in the medium and 0.1264 in the long term. In the mediumseverity area, values were $0.3333,0.0833$ and 0.1379 in short, medium and long terms, respectively. In the high severity area, values were $0.1538,0.0933$ and 0.1216 , respectively, in short, medium and long terms after wildfire. $\mathrm{D}$ was 2.1 in the control area in short, medium and long terms. The low-severity area presented values of 2.65, 3.7 and 4.35 in short, medium and long terms, respectively.
In the medium-severity area, values were $0.9,3.6$ and 4.35 , respectively, in short, medium and long terms. The high-severity area recorded values of 1.95, 3.75 and 3.7 in short, medium and long terms, respectively, after wildfire. All these values were calculated according to the main regenerative capacity of each species and were used in preparing figure 3 .

Specifically, based on their regenerative capacity, the $\mathrm{S}$ of resprouters was higher in the control area than in the other areas. Fifteen values were obtained in the control in short, medium and long terms. Low-, medium- and highseverity areas presented values of 4,5 and 7 in short, medium and long terms, respectively. H' presented a value of 0.3659 in the control area in short, medium and long terms; 0.1111 in the low-severity area in the short term, 0.1923 in the medium and 0.1556 in the long term. In the medium-severity area, values were $0.25,0.0962$ and 0.1207 in short, medium and long terms, respectively. The high-severity area recorded values of $0.1290,0.0769$ and 0.1129 in short, medium and long terms, respectively, after wildfire. D recorded a value of 2.1 in the control area in short, medium and long terms. The low-severity area
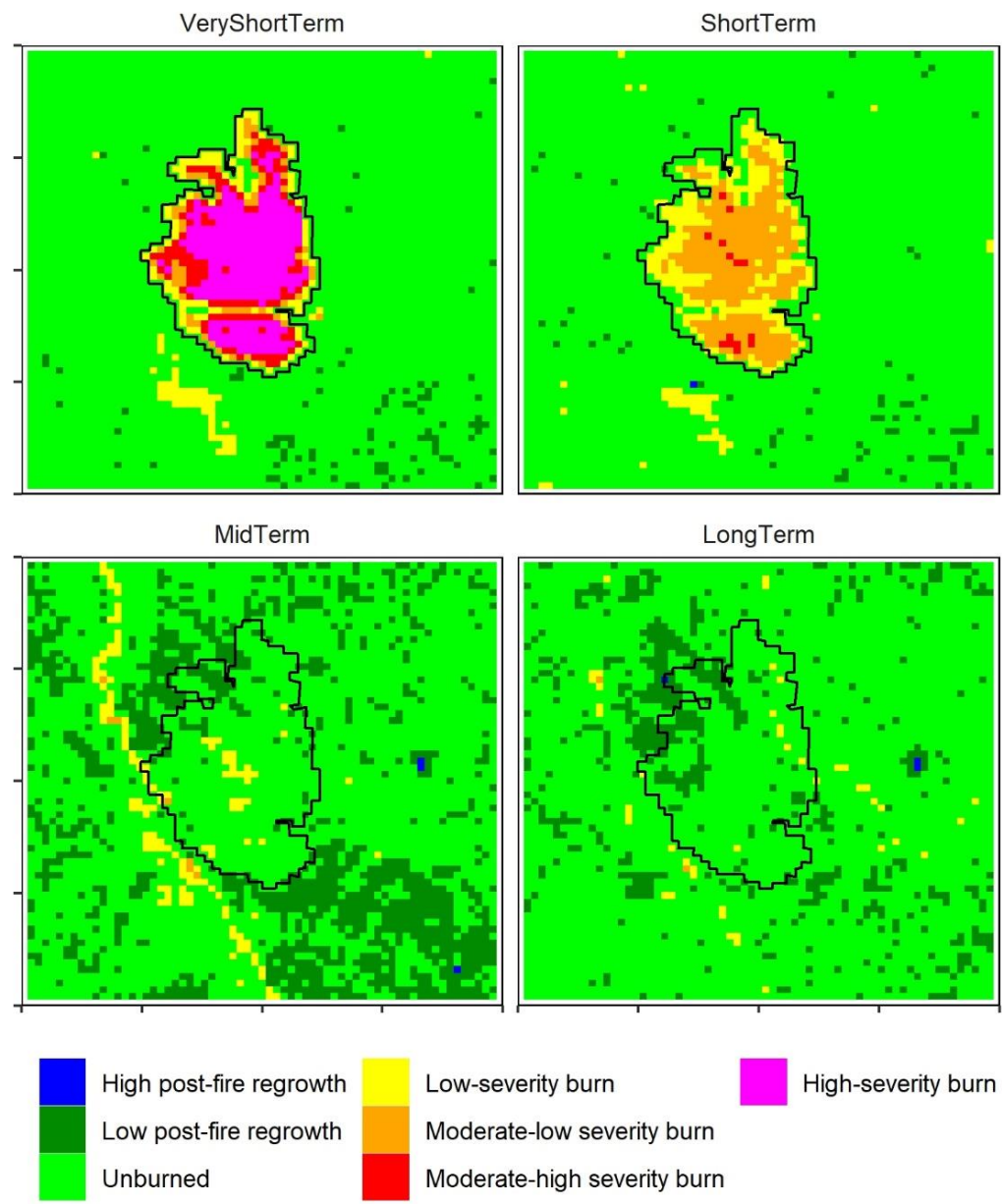

Low-severity burn

High-severity burn

Moderate-low severity burn

Moderate-high severity burn

Figure 3. Categorized dNBR for the very short-, short-, medium- and long-term dates after the wildfire.

Categorías de dNBR para muy corto, corto, medio y largo plazo después del incendio forestal. 
showed values of 1.8, 1.3 and 2.3 in short, medium and long terms, respectively. In the medium-severity area, values were $0.8,2.6$ and 2.9 in short, medium and long terms, respectively. The high-severity area recorded values of 1.6, 3.3 and 3.1 in short, medium and long terms after wildfire, respectively (figure 3 ).

The $\mathrm{S}$ of seeder species was higher in the control area than in the other areas. Values obtained were 2 in the control area in short, medium and long terms; 3 in the lowseverity area in the short term, 4 in the medium and 6 in the long term. In the medium-severity area, values were 3,3 and 6 in short, medium and long terms, respectively. In the high-severity area, values were 3, 4 and 4 in short, medium and long terms, respectively. H' presented value of 0.0476 in the control area in short, medium and long terms; 0.0566 in the low-severity area in the short term, 0.0541 in the medium and 0.0690 in the long term. In the medium-severity area, values were $0.1667,0.0417$ and
0.0690 in short, medium and long terms, respectively. In the high-severity area, the values recorded were 0.0769 , 0.0533 and 0.0541 in short, medium and long terms, respectively, after wildfire. D was 0.1 in the control area in short, medium and long terms. In the low-severity area values of 1.05, 2.9 and 2.35 were recorded in short, medium and long terms, respectively. In the medium-severity area, D values were $0.4,2.35$ and 2.35 , respectively, in short, medium and long terms. In the high-severity area values were 1.25, 2.1 and 1.75 in short, medium and long terms, respectively, after wildfire (figure 3 ).

Geospatial modelling of burn severity and their implications for forest management. In this section, we predicted the influence of three geographical covariates (i.e. altitude, slope-degree and pre-fire NDVI) on the severity of the burned area. However, not all predictors contribute to the same degree when modelling burn severity. Figure 4
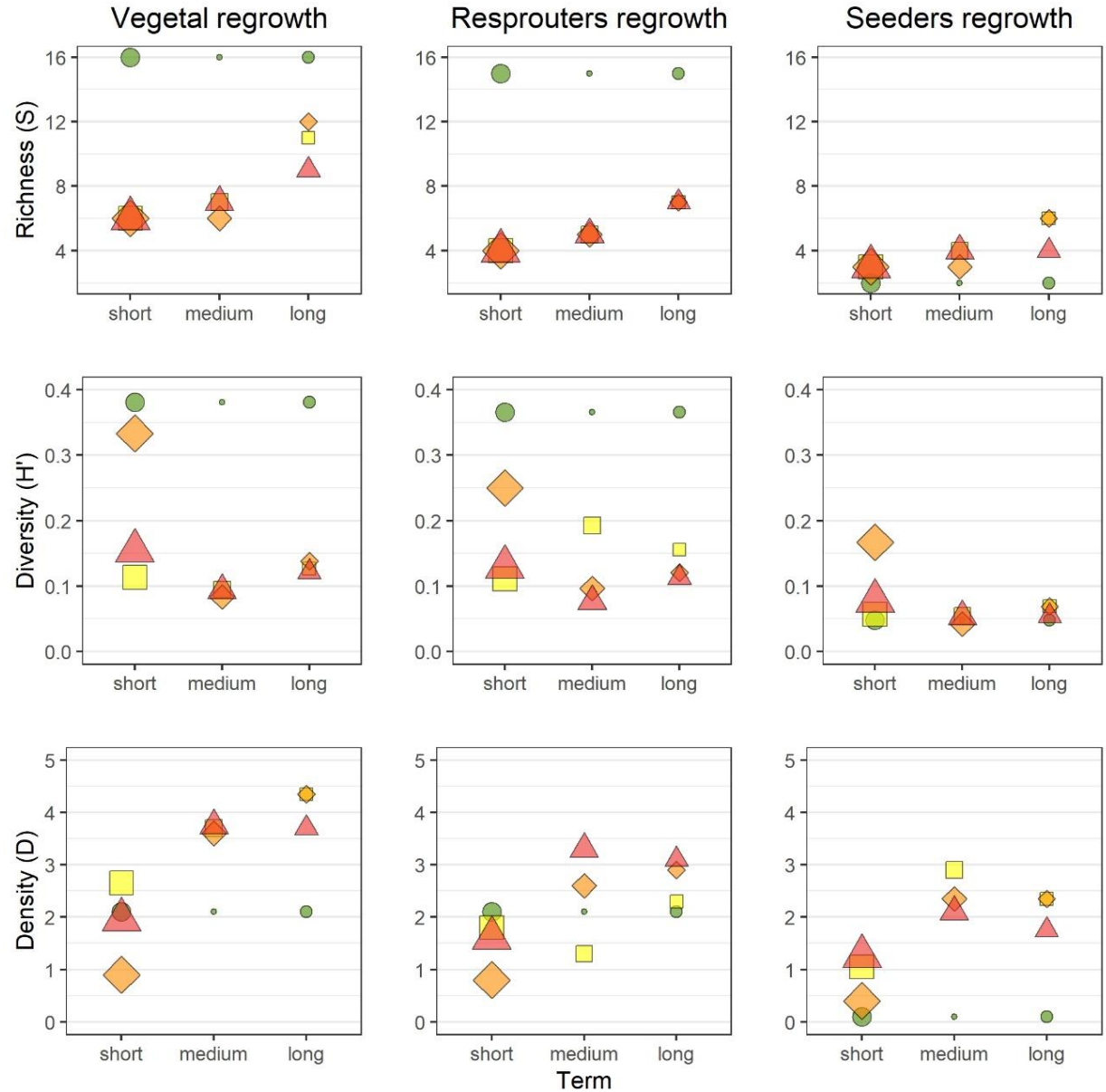

dNBR $\bullet-0.1$ 0.0 0.1 $0.2 \bigcirc 0.3$

Severity $\bullet$ Control $\square$ Low $\diamond$ Medium $\triangle$ High

Figure 4. dNBR index and Richness (S), Diversity (H') and Density (D) for each inventory sampling and in each area according to the regenerative capacity of the species (Resprouters and Seeders).

Índice dNBR y Riqueza (S), Diversidad (H') y Densidad (D) para cada muestreo de inventario y en cada área de acuerdo a la capacidad regenerativa de la especie (Rebrotadoras y Germinadoras). 
shows the importance (\%incMSE) of each covariable when predicting dNBR using random forest models.

As we move away from the date of the fire occurrence, in the short term, the influence of covariates begins to decrease and becomes less clear, although there are some exceptions. In the case of altitude, results continue to indicate that the areas presenting the highest severity were located at around $280 \mathrm{~m}$ a.s.l. In this case, it should be noted that vegetation growing at altitudes higher than $280 \mathrm{~m}$ a.s.l. recovered more quickly than that growing below this altitude. As for slope, there was little change regarding very short term outcomes - there being two maximum peaks of severity on slopes of 10 and $12^{\circ}$ and two minimum peaks on slopes between 23 and $25^{\circ}$ - although these were not appreciated so clearly as in the very short term. The prefire NDVI continued to present a pattern that was basically very similar to that in the very short term, which meant that the vegetation with higher NDVI values continued to be the one that recovered the quickest.

In the medium term, highly significant changes were recorded as vegetation was no longer burned, and altitude did not account for the spatial distribution of dNBR. In the case of slope, the pattern of vegetative recovery was higher on slopes exceeding $20^{\circ}$ than it was on slopes of around $10^{\circ}$, especially given that the latter were the ones that had suffered the most severe burn. As for NDVI, the areas with the highest values were those that recovered the most. In the long term, no appreciable differences with medium-term results suggest that the effects of fire and its severity could no longer be easily detected by remote sensing (figure 5).
Figure 5 shows how, when predicting dNBR in the very short term by slope and altitude, we found a maximum focus of severity at a slope of $10^{\circ}$ and an elevation of $280 \mathrm{~m}$ a.s.l. The same pattern was repeated in the short term, though was clearly not evident in medium and long terms. On the other hand, in the case of the influence of NDVI and altitude on dNBR, we observed that in the very short term, maxima were recorded at values between 0.65 and 0.7 of NDVI and at an altitude of around $280 \mathrm{~m}$ a.s.l. In the short term, the same pattern was repeated, though with lower intensity. In the medium term, the influence persisted, albeit more weakly, at coordinates of $275 \mathrm{~m}$ a.s.l. and an NDVI of 0.65 . In the long term, there was a shift in pattern between altitude and NDVI to the point that it appears to disconnect from the effects of the fire. A study of the joint influence of NDVI and slope allowed us to perceive the same situation as the one outlined above. In the very short term and in the short term, a maximum dNBR was observed in NDVI ranges between 0.6 and 0.8 and between 10 and $20^{\circ}$ of slope, nonetheless above all around $10^{\circ}$. In the medium term, the influence of NDVI and slope on dNBR weakened, becoming non-existent in the long term (figure 6).

\section{DISCUSSION}

Vegetation recover. According to Francos et al. (2016), the areas affected by wildfire in our study area are fully recovered in the long term. Immediately after a fire, herbs are the first community to emerge and to colonize bare soil.

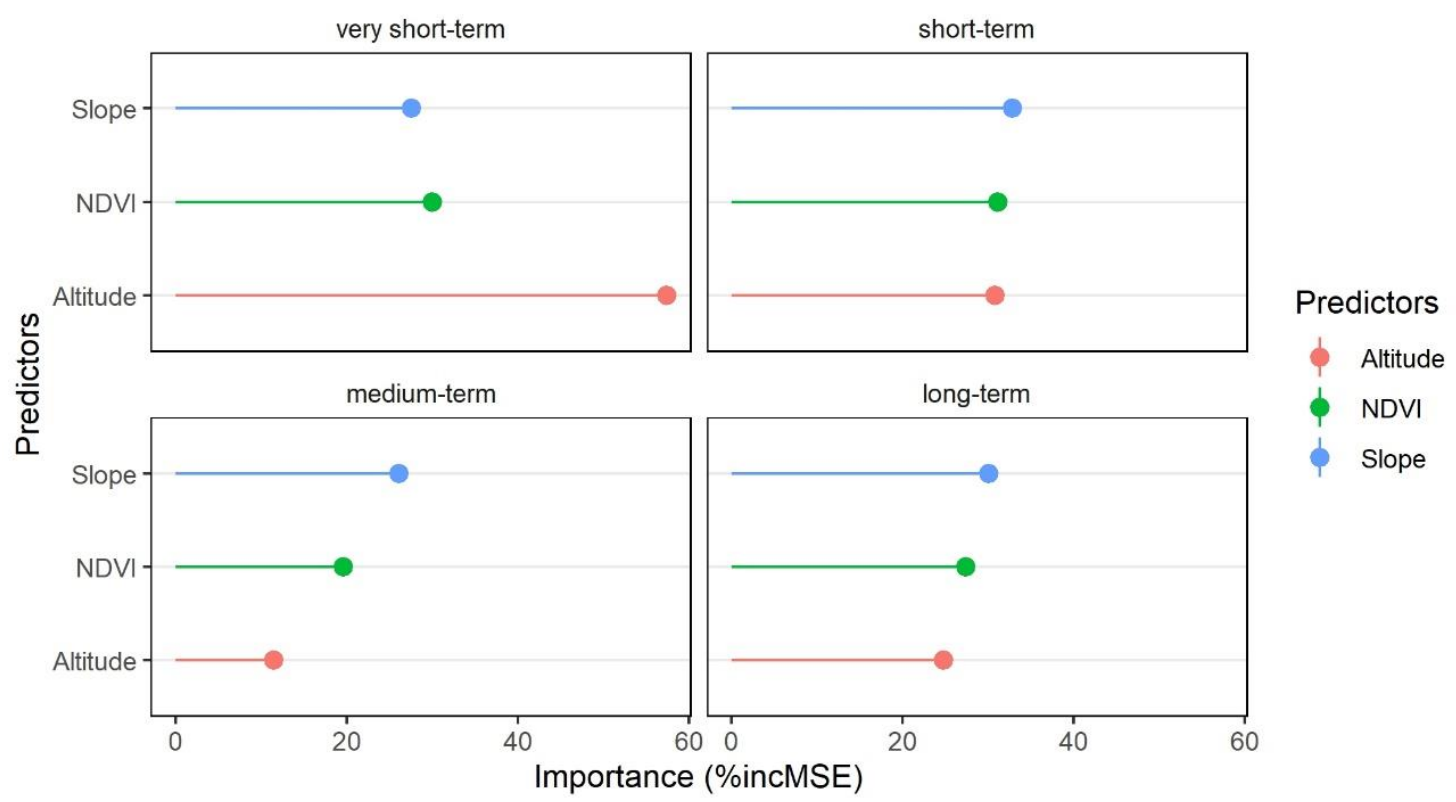

Figure 5. Importance of variables used in random forest modeling. \%IncMSE indicates the increase in the mean squared error when a given variable is randomly permuted.

Importancia de las variables utilizadas en la modelización forestal aleatoria. El \%IncMSE indica el aumento del error cuadrático medio cuando una determinada variable se permutó aleatoriamente. 
Three years after the fire episode, they disappear due to successional dynamics and intra- and inter-specific competition (Bond and Keeley 2005). As noted, long-term after the wildfire, the vegetation in area a) was composed mainly of herbs while tree cover constituted an important part of the total vegetation. With increasing fire severity, the predominant life form was no longer herbs but shrubs, and tree cover became quite scarce. Many factors are responsible for these differences in long-term vegetation recovery post-fire: most notably, wildfire severity, forest management (Santana et al. 2011) and inter-specific vegetation competition (Madrigal et al. 2011). Here, and despite the evidence of the impact of fire severity on plant recovery, the area presents a high long-term vegetation density. The fact that the long-term vegetation in area c) is composed mainly of shrubs produces considerable fuel continuity and high vegetation density. In such a situation, it is necessary to implement sustainable forest management practices to reduce the risk of wildfire.

Comparison of methods and statistical analyses. The dNBR is one of the of the most frequently used severity indicators (Key and Benson 2006). In the present study, dNBR fell over time, disturbance was lower in vegetation recovery in both resprouters and seeders, while long-term dNBR values were similar in the control area and those areas affected by fires of different degrees of severity. The control area is characterized by dNBR $<0.1$ and, in the long term, the dNBR values of burned areas are similar to those of the control when there are no longer any signs of fire disturbance (Fuentes-Ramírez et al. 2018). Control richness dynamics is mainly dominated by resprouters and is significantly higher in the control than in fire-affected areas at all sampling dates. The richness of the seeders is
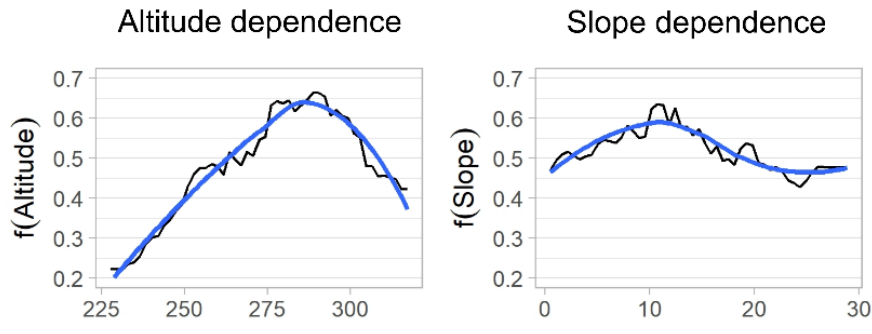

\section{Pre-fire NDVI dependence}
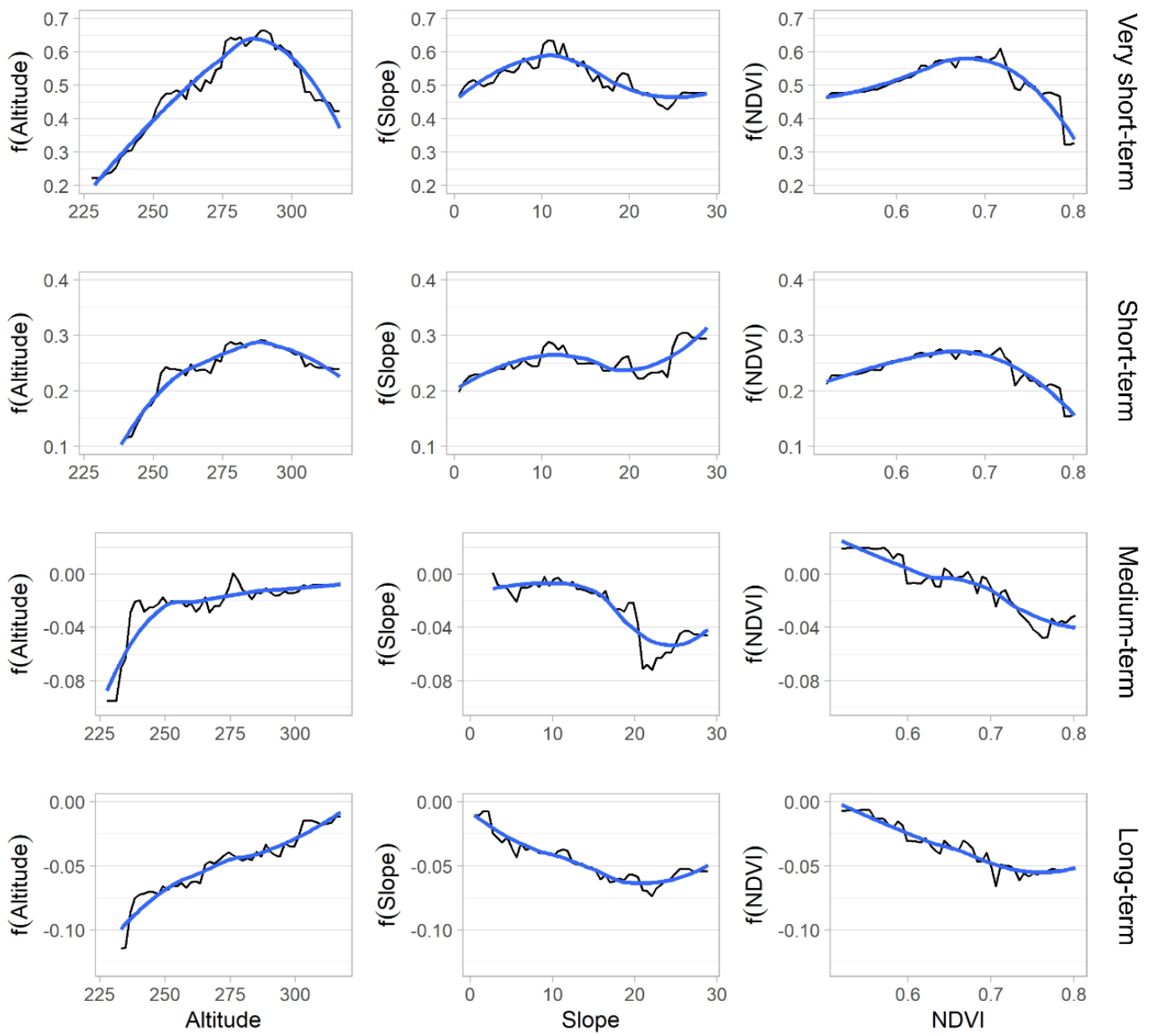

Figure 6. Random Forest partial dependence plots for selected predictor variables. Plots indicate the dependence of differenced normalized burn ratio on each topographic predictor and at different points in time after the wildfire.

Gráficas de dependencia parcial de Random Forest para las variables predictivas seleccionadas. Las gráficas indican la dependencia de dNBR en cada predictor topográfico y en diferentes momentos del tiempo después del incendio forestal. 
Very short-term
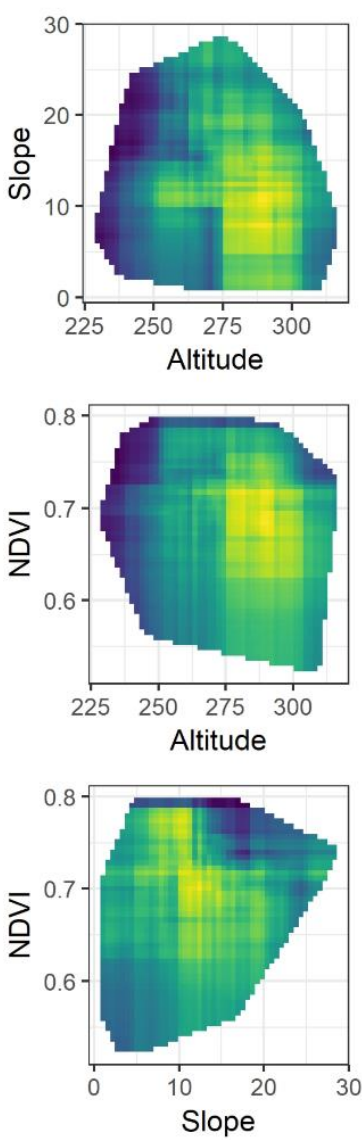

dNBR

0.20 .30 .40 .50 .60 .7
Short-term
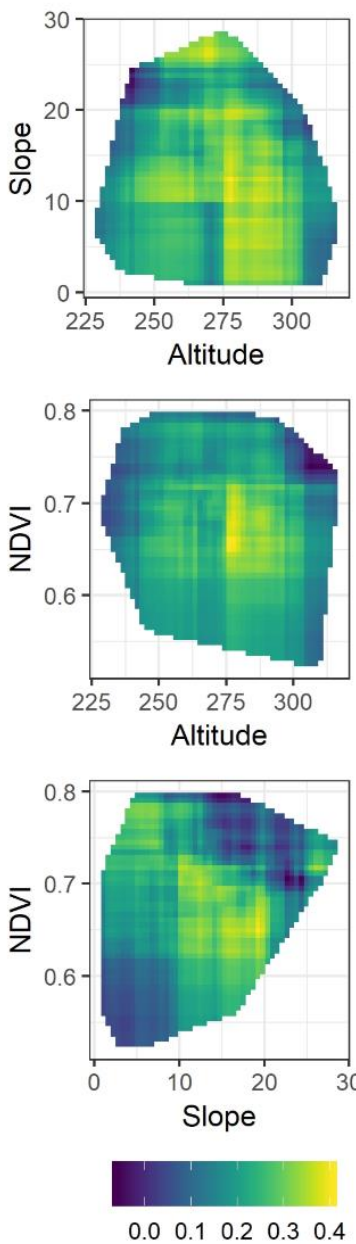

Medium-term
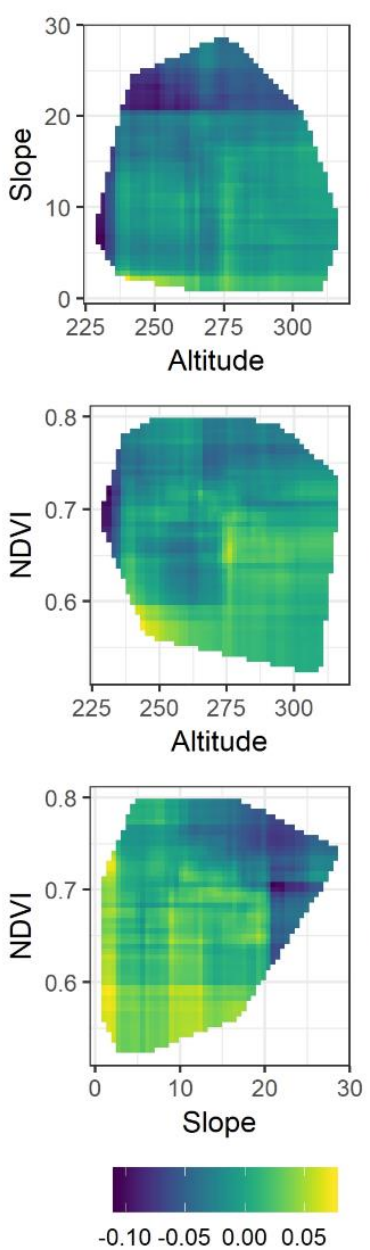

Long-term
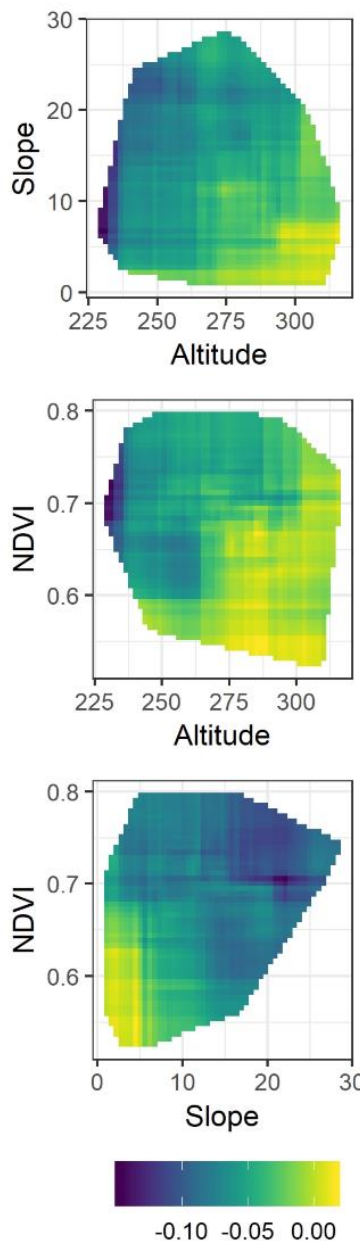

Figure 7. Multi-predictor partial dependence plots for selected predictor variables. Three combinations (slope vs altitude, NDVI vs altitude and NDVI vs slope) were analyzed at four different points in time after the wildfire.

Gráficas de dependencia parcial de múltiples predictores para variables de predicción seleccionadas. Se analizaron tres combinaciones (pendiente frente a altitud, NDVI frente a altitud y NDVI frente a pendiente) en cuatro momentos diferentes después del incendio forestal.

very low in the control area at all inventory samplings due to the absence of fire disturbance and the absence of the vegetation colonization process (Keeley et al. 2011). The dNBR values for plant density, in common with those for richness and diversity, were very similar in all fire-affected areas. The dNBR values were higher in fire-affected areas and decreased over time, indicative of complete plant recovery after exposure to different fire severities and the ability of this ecosystem to adapt to wildfires (FuentesRamírez et al. 2018). Some species, known as facultative seeders, show a dual recovery capacity (Pausas and Keeley 2014), however here most species present are either obligate resprouters or obligate seeders.

Richness (S) was significantly lower in burned areas than in the control. We recorded higher plant richness (S) over time in three burned areas mainly due to the contribution made by resprouters. Calvo et al. (2005) observed an increase in plant cover and density up to four years after fire as well as an increase in richness between four and five years after the event in a fire-adapted ecosystem, in line with findings reported in the present study. The lower richness values in the high-severity fire-affected area persisted from short to long terms after wildfire. Fuentes-Ramírez et al. (2018) observed the same lower values in high-severity fire-affected areas one year after fire (as expected) due to ignition. In this sense, the authors noted, as in the current study, a slow increase in vegetation richness over time. In our study, richness (S) remained lower than in the unburned area until the long term after fire. Richness showed lower values in the high-severity area than in the other burned areas due to the fall in seeder recovery with time.

Vegetation diversity ( $\left.\mathrm{H}^{\prime}\right)$ showed significantly higher values in the control than in the fire-affected areas in all the periods due to the absence of fire disturbance. Rodríguez- 
Trejo et al. (2019) determined that the differences in plant $\mathrm{H}$ ' in different fire severity areas, compared to unburned areas, disappear in a few months or years. In this study, fire led to a change in forest structure and although it did not affect plant recovery capacity, it did modify the forest species present, thus impacting richness, diversity and density indices. González-De Vega et al. (2016) observed significantly lower plant diversity in fire affected areas than that observed in the control until the medium term due to the reduction in the seedbank. A difference between fire severities can be highlighted, with diversity being higher in mediumseverity areas, while they observed changes in post-fire recovery patterns (González-De Vega et al. 2016). Diversity was significantly higher in the medium-severity area in the short term after fire as a result of the important contribution made by both resprouters and seeders, although it decreased over time, becoming similar to the values recorded in the other areas in medium and long terms. Diversity in the high-severity fire affected area was higher in the short than in medium and long terms due to the contribution made by resprouters. In medium and long terms, the diversity values obtained in the high-severity area were similar to those obtained in the other burned areas.

Vegetation density (D) in the control, as occurs also with plant richness and diversity, is mainly determined by resprouters and remains stable throughout the study period. In this sense, the post-fire dynamics of resprouters is especially fast, due to the well-developed system of roots capable of capturing water and nutrients (Keeley et al. 2011). In this case, in the short term after fire, density values are lower in medium- and high-severity areas than they are in the control. Only in the case of low-severity fires density was higher than that in the control. The seeder community in the control is significantly smaller than that in fire-affected areas owing to the absence of any fire disturbance (Keeley et al. 2011). As regards richness, diversity and density, fire increases seeder germination raising the values of these indices to levels higher in fire affected areas than in the control (Pausas and Keeley 2014). In fire affected areas the increase in seeder vegetation communities (as reported herein) has been noted, with fire serving to promote germination. In this sense, Keeley et al. (2011) highlighted the need for a thermal shock to break the seed dormancy. Low-, medium- and high-severity areas showed significantly higher values than those shown by the control in medium and long terms after fire. In the case of the low-severity area, this is attributable to the marked increase in seeder communities, especially in the medium term. Malak et al. (2015) also observed a short-term increase in resprouters (1-3 years) after fire. Subsequent to this, in the medium term (in common with the findings reported herein), the area density mainly comprises seeding shrub communities. After 8 years, as occurred in the long-term density index in all burned areas of this study, seeders decrease and vegetation tends to stabilize as a result of community senescence (Malak et al. 2015). Rodriguez-Trejo et al. (2019) noted that low-severity fires favor the occupation of burned area by seeders and that high-severity fires tend to boost the recovery of resprouter species after fire, as occurred in terms of density in the present study in medium and long terms. This occurs as a result of high temperatures - the case in high-severity fires, which affect the phytohormones that inhibit resprouting while root cytokinins stimulate the recovery of resprouters. In the case of high-severity fire affected areas, density is higher in the medium term than in the long term, controlled mainly by resprouters in short, medium and long terms. High-severity fires result in the destruction of seedbanks (Maia et al. 2012) affecting the capacity of seeders to recover and facilitating the presence of resprouters. Density increases significantly between short and medium terms, as reported by Calvo et al. (2005). Plant cover density was significantly higher in burned untreated areas than it was in simply untreated tracts, as occurred in this study medium and long terms after wildfire (Calvo et al. 2005). The density in all fire-affected areas was significantly higher than in the control, and increased over time. In this respect, low-severity fires stimulate seed germination and high-severity fires result in seed mortality (Maia et al. 2012), as observed here in the higher seeder densities in medium and long terms after the low-severity fire. The same results were reported by González-De Vega et al. (2016), the density of seedling plants being higher in low- and medium-severity areas, in line with the results presented herein. Keeley (2009) did not, however, observe a correlation between fire severity and complete vegetation recovery, concluding that plant recovery was superior in high-severity areas. As in this study (see density results in figure 3), high fire severity does not represent a limit to the recovery of resprouters, rather to that of seeders (Keeley, 2009). In this respect, to avoid a potential occurrence of wildfires and to reduce the risk of wildfire, it is essential to carry out sustainable forest management (explained in the section below).

Vegetation field inventories and dNBR provided good results in this multi-approach study for assessing plant recovery capacity after wildfire, as shown by density (D) results. In the cases of richness (S) and diversity (H'), however, we needed to carry out fieldwork inventories to detect variations in these indexes. Martínez et al. (2019) point out that such relevant information as vegetation richness and diversity are not observable with remote sensing nevertheless the tool is useful to analyze the density of vegetation recovery as it provides a large quantity of spatial information. Therefore, this index can be very useful not only to analyze post-fire vegetation regeneration, but also to establish the hotspots where management is needed to avoid catastrophic wildfires (Bento-Gonçalves et al. 2019).

Geospatial modelling of burn severity and their implications for forest management. According to results, altitude had an important impact on burn severity (57.4\%), well above that of pre-fire NDVI (30\%) and slope (27.6\%). 
The whole model reported an explained a variance of $30.34 \%$ and an $\mathrm{R}^{2}$ of 0.29 , which means that the severity of the fire was marked by altitude. However, this same distribution of importance was undetected in the short term, when the weighting was more equally distributed among the three predictors. In this particular instance, predictors together explained a lower variance $(18.2 \%)$. In the medium term, there was a shift in the importance of covariates. Slope acquired a relative importance of $26.1 \%$, while NDVI and altitude were reported at 19.6 and $11.5 \%$, respectively. Finally, in the long term, the pattern was similar to that found in the medium term; however, an increase in importance was detected in all covariates and also in the explained variance $(26.13 \%)$ and $\mathrm{R}^{2}(0.25)$. As such, slope appears as one of the most important factors in plant recovery alongside fire severity.

The use of PD plots sheds some light on the relationship between predictor variables and dNBR (figure 4). In the very short term, altitude was, as discussed above, clearly linked to the severity of the burn. In fact, burn severity was seen to be much lower at lower altitudes. However, the highest burn severity occurred at around $280 \mathrm{~m}$ a.s.l., which does not coincide with the highest zone in the study area. This can be attributed to the fact that topography limited the growth of vegetation in high slope areas, as noted previously by Madrigal et al. (2005). The slope covariable also presented a non-linear relationship with dNBR. Although fire severity was high for all slope values, there was a clear upsurge in areas with slopes around $10-12^{\circ}$; yet, both above and below this slope range, severity was not as high. This might be attributable to strong soil wash (Francos et al. 2016) associated with the processes of erosion or to limitations associated with areas of high slope (Madrigal et al. 2005). Plant recovery after wildfire is hindered on slopes given their larger vulnerability to water and wind. Pre-fire NDVI was quite stable, nevertheless when reaching values higher than 0.7 burn severity started to decline. This coincides with the fact that the area where the pre-fire vegetation status was healthier suffered less severe burning.

In this study, we characterized the effects of topography on the severity of burning. Our results reveal relevant topographic and pre-fire vegetation patterns in very short and short terms after wildfire. However, we found no clear relationship between the burned area and the area topography and pre-fire vegetation status in medium and long terms. Some studies reported a considerable influence of topographic factors on fire severity finding that slope and elevation were the two most important topographic variables and that severe fires were most likely to occur in higher elevations, as we reported herein. Elevation has previously been considered a highly influential predictor variable of fire severity in Dillon et al. (2011). This finding would explain why slopes between 10 and $12^{\circ}$ had the highest burn severity in our study area. General linear models were used to show that fire severity on steeper slopes was more extreme than that on gentle slopes in pine forests.
As for the effect of vegetation on fire severity, Chen et al. (2011) reported that high burn severity areas present a much slower recovery than that presented by moderate and low burn areas, hence the healthiest areas before the fire are also those that are exposed to fires of least severity. These same dynamics were found in our study, although on a smaller scale and with less intensity, by means of the partial dependence plot between NDVI and dNBR.

According to Madrigal et al. (2011), in Mediterranean ecosystems, management is not necessary to ensure that post-fire revegetation is able to return rapidly to its pre-fire conditions, as observed here in our dNBR analysis. Despite this, the absence of management affects vegetation recovery and forest plant composition (Santana et al. 2011). Shortterm forest management practices (Santana et al. 2011) may, however, hinder complete plant recovery because of the damage caused to the seed bank. For this reason, and because of the associated environmental degradation, Francos et al. (2016) recommend medium- or long-term post-fire treatments to reduce plant density and wildfire risk and to avoid any deterioration in soil properties. Various authors, including Keeley et al. (2011), noted that to reduce the risk of wildfire and to implement sustainable fire risk prevention, it is necessary to promote frequent, severe fires at similar levels to those recorded in sustainable fire regimes.

\section{CONCLUSIONS}

To gather the required field data is not always a straightforward process. Often it is only possible to obtain remote sensing data though with little opportunity to validate them on the ground. Here, both field and remote sensing data were available, enabling us to conduct a multi-approach assessment. Based on the values obtained for the dNBR of vegetation recovery, Mediterranean forests show a high capacity to adapt to wildfire disturbance in the long term after a fire episode, with control values being very similar to those recorded in low-, medium- and high-severity burned areas. Richness and diversity values presented similar patterns, though they were higher in the control due to the specific contribution of the resprouter communities which control the dynamics in burned (low, medium- and high-severities) and unburned areas (control). Density was lower in the control than in the lowseverity fire area in the short term. Indeed, the low-severity area is the only area in which the main contribution to the density of vegetation recovery, in medium and long terms, is made by seeders. Density increased over time in burned areas and was higher than it was in the control in medium and long terms primarily due to the dynamics of the resprouters in medium- and high-severity fire areas. The multiple approach method employing both remote sensing and fieldwork data provided a good approximation for the study of the vegetation recovery capacity in a Mediterranean forest. Additionally, the results obtained from random forest modeling allow us to conclude that topographic and 
vegetation variables help explain the severity of burning in very short and short terms, while in medium and long terms any explanatory power is virtually lost. The use of partial dependence plots allowed us to identify those areas of the study area that suffered high severity of burning and the way in which they evolved at different sampling times. In short, the study conducted here has made it possible to deeply investigate the relationship between field and remote sensing data in wildfire studies. Moreover, the influence of topographic variables and pre-fire vegetation status on the severity of burning has also been highlighted.

\section{ACKNOWLEDGMENTS}

This study was supported by the POSTFIRE_CARE Project (CGL2016-75178-C2-2-R [AEI/FEDER, UE]) financed by the Spanish Research Agency (AIE) and EU's Regional Development Fund (FEDER) and Project 2017SGR1344 funded by Generalitat de Catalunya. We wish to thank Iain Robinson (SL-UB) for revising the English manuscript and Xavier Úbeda and Joan Albert López-Bustins from University of Barcelona (UB) for supporting the basic premise underpinning this study. ML-C is the recipient of a pre-doctoral FPU Grant (FPU2017/02166) from the Spanish Ministry of Science, Innovation and Universities. Both authors have contributed in the same way to this paper. No potential conflict of interest was reported by the authors.

\section{REFERENCES}

Bento-Gonçalves A, A Vieira, G Baptista, J Rocha, S Moura. 2019. The 2017 Large Wildfire of Braga-Evaluation of the Different Conditions of the Burned Vegetation. Geo-Eco-Trop 43(4): 627-640.

Bond WJ, JE Keeley. 2005. Fire as a global 'herbivore': the ecology and evolution of flammable ecosystems. Trends Ecology \& Evolution 20(7): 387-394. DOI: 10.1016/j.tree.2005.04.025

Breiman L. 2001. Random Forests. Machine Learning 45: 5-32. DOI: 10.1023/A:1010933404324.

Calvo L, R Tárrega, L ED, L Valbuena, E Marcos. 2005. Recovery after experimental cutting and burning in three shrub communities with different dominant species. Plant Ecology 180(2): 175-185. DOI: $10.1007 / \mathrm{s} 11258-005-0200-\mathrm{Z}$

Chavez Jr PS. 1988. An improved dark-object subtraction technique for atmospheric scattering correction of multispectral data. Remote Sensing of Environment 24(3): 459-479. DOI: $\underline{10.1016 / 0034-4257(88) 90019-3}$

Chen X, JE Vogelmann, M Rollins, D Ohlen, CH Key, L Yang, C Huang, H Shi. 2011. Detecting post-fire burn severity and vegetation recovery using multitemporal remote sensing spectral indices and field-collected composite burn index data in a ponderosa pine forest. International Journal of Remote Sensing 32: 7905-7927. DOI: 10.1080/01431161.2010.524678

Dillon GK, ZA Holden, P Morgan, MA Crimmins, EK Heyerdahl, CH Luce. 2011. Both topography and climate affected forest and woodland burn severity in two regions of the western US, 1984 to 2006. Ecosphere 2: 1-33.
Francos M, P Pereira, X Úbeda. 2020. Effect of different preand post-wildfire management practices on plant recovery after a wildfire in NE Iberian Peninsula. Journal of Forestry Research 31(5): 1647-1661. DOI: 10.1007/s11676-01900936-7.

Francos M, X Úbeda, J Tort, JM Panareda, A Cerdà. 2016. The role of forest fire severity on vegetation recovery after 18 years. Implications for forest management of Quercus suber L. in Iberian Peninsula. Global and Planetary Change 145: 11-16.

Fuentes-Ramírez A, M Barrientos, L Almonacid, C ArriagadaEscamilla, C Salas-Eljatib. 2018. Short-term response of soil microorganisms, nutrients and plant recovery in fire-affected Araucaria araucana forests. Applied Soil Ecology 131: 99106.

González-De Vega S, J de las Heras, D Moya. 2016. Resilience of Mediterranean terrestrial ecosystems and fire severity in semiarid areas: Responses of Aleppo pine forests in the short, mid and long term. Science of the Total Environment 573: 1171-1177.

Greenwell BM. 2017. pdp: An R Package for Constructing Partial Dependence Plots. R Journal 9(1).

Keeley JE. 2009. Fire intensity, fire severity and burn severity: a brief review and suggested usage. International Journal of Wildland Fire 18(1): 116-126.

Keeley JE, WJ Bond, RA Bradstock, JG Pausas, PW Rundel. 2011. Fire in Mediterranean ecosystems: ecology, evolution and management. Cambridge, UK. Cambridge University Press. 522 p.

Key CH, NC Benson. 2006. Landscape assessment. Sampling and analysis methods. Firemon: Fire effects monitoring and inventory system. General Technical Report. USDA Forest Service, Rocky Mountain Research Station, Fort Collins CO., RMRS-GTR-164-CD, USA, 400 p.

Madrigal J, C Hernando, M Guijarro. 2011. El papel de la regeneración natural en la restauración tras grandes incendios forestales: el caso del pino negral. Boletín del CIDEU 10: 5-22.

Madrigal J, C Hernando, E Martínez, M Guijarro, C Díez. 2005. Regeneración postincendio de Pinus pinaster spp. En la Sierra de Guadarrama (Sistema Central, España): modelos descriptivos de los factores influyentes en la densidad inicial y la supervivencia. Investigación Agraria. Sistemas y Recursos Forestales 14: 36-51.

Maia P, JG Pausas, V Arcenegui, C Guerrero, A Pérez-Bejarano, J Mataix-Solera, MET Varela, I Fernandes, ET Pedrosa, JJ Keizer. 2012. Wildfire effects on the soil seed bank of a maritime pine stand - the importance of fire severity. Geoderma 191: 80-88.

Malak DA, JG Pausas, JE Pardo-Pascual, LA Ruiz. 2015. Fire recurrence and the dynamics of the enhanced vegetation index in a Mediterranean ecosystem. International Journal of Applied Geospatial Research 6(2): 18-35.

Martínez S, I Aguado, E Chuvieco. 2019. Remote sensing techniques applied to post-fire regeneration. In Pereira P, MataixSolera J, Úbeda X, Rein G, A Cerdà eds. Fire effects on soil properties. Clayton, Australia. CSIRO Publishing. p. 347-370.

Parks SA, GK Dillon, C Miller. 2014. A new metric for quantifying burn severity: the relativized burn ratio. Remote Sensing 6(3): 1827-1844.

Pausas JG, JE Keeley. 2014. Evolutionary ecology of resprouting and seeding in fire-prone ecosystems. New Phytologist 204(1): 55-65. 
Rodríguez-Trejo DA, JG Pausas, AG Miranda-Moreno. 2019. Plant responses to fire in a Mexican arid shrubland. Fire Ecology 15(1): 11. DOI: $10.1186 / \mathrm{s} 42408-019-0029-9$.

Santana J, M Porto, L Reino, P Beja. 2011. Long-term understory recovery after mechanical fuel reduction in Mediterranean cork oak forests. Forest Ecology and Management 261: 447-459.
Úbeda X, LR Outeiro, M Sala. 2006. Vegetation recover after a differential intensity forest fire in a Mediterranean environment, northeast Spain. Land Degradation \& Development 17(4): 429-440.

Zheng Z, Y Zeng, S Li, W Huang, Z Zheng, Y Zeng, S Li, W Huang. 2018. Mapping Burn Severity of Forest Fires in Small Sample Size Scenarios. Forests 9: 608.

Recibido: 09/12/20

Aceptado: 21/06/21 